International Journal of Instruction e-ISSN: 1308-1470 • www.e-iji.net

Article submission code: 20200907082304

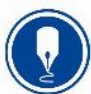

October $2021 \bullet$ Vol.14, No.4

p-ISSN: 1694-609X

pp. 733-752

Received: 07/09/2020

Revision: 19/04/202
Accepted: 14/05/2021

OnlineFirst: 02/09/2021

\title{
Perceived Psychological, Linguistic and Socio-Cultural Obstacles: An Investigation of English Communication Apprehension in EFL Learners
}

\author{
Sameena Malik \\ Corresponding author, Department of Foreign Languages, Huazhong University of \\ Science \& Technology, China, sameenamalik@hust.edu.cn \\ Huang Qin \\ Dean of Translation and MIT Research Centre, Department of Foreign Languages, \\ Huazhong University of Science \& Technology, China, huangqin@hust.edu.cn

\section{Ibrahim Oteir} \\ Asst. Prof., Preparatory Year Program, Batterjee Medical College, Saudi Arabia, \\ ibrahim.oteir@bmc.edu.sa
}

\begin{abstract}
Speaking and communicating in English language can be a traumatic experience for many Chinese EFL university learners in class and in public. In many situations, they prefer to remain silent and passive listeners. This study aims to detect linguistic, psychological, socio-cultural hindrances and lends a sympathetic ear to Chinese university EFL learners enrolled in a public sector university in Wuhan and sheds light on their perspective that cause apprehension in communicating English as a FL/SL. Horwitz's FLA, Krashen's input hypothesis, affective filter hypothesis, Tanveer's learners' perspective, Vygotsky's and Feuerstein's social constructivism have been used as theoretical frameworks. The present study employed a qualitative method for collecting data and directed content analysis was conducted with deductive and inductive approach. Focus group discussion and semi-structured interviews were conducted with eight Chinese EFL university students within an academic and social context. The respondents were from social sciences discipline and had enrolled in fall semester for attending one course of English oral communication skills in the department of FL. The results of the directed content analysis indicated that respondents experienced communication apprehension and anxiety due to their own self-related psychological, cognitive, linguistic, academic, social and cultural aspects. They felt anxiety due to personality traits, low language proficiency, perceived academic issues, scholastic competence, poor pronunciation, and above all lack of lexical knowledge in TL.
\end{abstract}

Keywords: apprehension, anxiety, communication, perceived psychological, linguistic, socio-cultural obstacles

Citation: Malik, S., Qin, H., \& Oteir, I. (2021). Perceived psychological, linguistic and socio-cultural obstacles: An investigation of English communication apprehension in EFL learners. International Journal of Instruction, 14(4), 733-752. https://doi.org/10.29333/iji.2021.14442a 


\section{INTRODUCTION}

Communitive competence and proficiency in speaking English as a SL/FL have already been established as a threshold for success in numerous countries and societies (Gökcan \& Aktan, 2019). Speaking is an essential skill in foreign or second language acquisition. In fact, it is very stressful and emotional process that is likely to induce reticence in second language learners. Some people being bilingual or multilingual prefer to use two or more languages. Usually it is believed, that in this era of advancement, people with one language are the endangered species of the universe (Gökcan \& Aktan, 2019). Apprehension is an emotional, physical response to an anticipated danger or situation that affects the capability to think and process information and has cognitive, psychological as well as controlling aspects and elements (Asif et al. 2020). This cognitive part intervenes with an academic and communication process and affects the thinking process as well (Malik et al. 2020). Apprehension affects an individual's goals, careers, life style, behaviour and even identities. One of the most significant and inevitable factors that often hinders SLA process in language acquisition device (LAD) is called Communication Apprehension (CA). Communication reticence being an important psychological factor affects various other factors like cognitive, affective, contextual or particular circumstances in the process of the complex language acquisition process.

This multidimensional and intricate phenomenon of CA was conceptualized by McCroskey (1977) in the United States and according to him, CA is "an individual's level of fear or anxiety associated with either real or anticipated communication with another person or persons. The term Communication apprehension and speaking anxiety have been used interchangeably in existing literature (Tanveer, 2007a). CA is considered to be prevalent at the macro level in China due to the number of factors i.e., lack of English communication practice and activities in class and less exposure to the foreign language out of class, interlocutors' use of L1 and many other psychological, the socio-cultural and the linguistic factors (Malik et al. 2020; Shan, Hussain, \& Sargani, 2020). According to research, Confucian countries like Japan, Korea and China are more anxious in speaking FLS/SL (Woodrow, 2006). In 1980, a policy was introduced in which it was made obligatory by the China Ministry of Education for Chinese university learners to learn College English as a FL/SL in the initial two years of the university (Jie \& Xiaoqing, 2006). After that, they have to pass the College English Test with at least band 4 (CET-4) for fulfilling the requirement of Bachelor's degree (Tian, Wei, \& Li, 2019). The Significance of the English as a FL in mainland China is growing with every passing day, and Chinese students are more proficient in reading, writing and listening as compared to speaking and communication skills (Murad \& Jalambo, 2019). Numerous Chinese EFL university learners face CA and anxiety in FL speaking and this factor adversely hinders their English communication skills. Communication anxiety has been researched by psycholinguists in different contexts in Asian countries and China, still this area needs plenty of attention (Hu, 2003; Malik et al. 2020; Wang \& Ding, 2001). Many studies have addressed the issue of language anxiety quantitatively across the globe yet, there is dearth of qualitative research on CA inducing factors from the perspective of Chinese EFL university learners (Tuncel et al. 
2020; Wan, Yan, \& Gong, 2020). Being a part of the Chinese university as PhD researchers, we have observed apprehension and anxiety while talking and interacting with Chinese EFL students in different disciplines and that they feel apprehension and hesitation in speaking English in class and out of class. This observation has motivated us to address the FL/SL speaking apprehension through research in order to create awareness among Chinese EFL university learners in particular and others in general to tackle this issue and dig out causes.

As there is lack of qualitative studies on CA in Chinese context, and this issue needs more attention, therefore, taking this as a gap, this study aims to detect linguistic, psychological, socio-cultural hindrances and sheds light on their perspective that cause $\mathrm{CA}$ and anxiety in speaking, and communicating English as a FL/SL. Detecting the factors and variables that induce speaking anxiety among Chinese EFL university leaners have been the main objectives of this research. Identifying the sources that affect EFL learners' communication skills may be beneficial for language educators and policy makers in devising effective strategies for this multifaceted phenomenon. This research would enrich the existing literature and it is expected that this study can enlighten educators and interlocutors in Asian context in general and Chinese in particular on the necessary measures to be adopted in order to mitigate the apprehension burden carried by numerous EFL university learners that would ultimately benefit in improving their English communication skills. Realizing the significance of English communication skills across the globe and in China, the current research may be supportive for FL/SL teachers, university students and stakeholders to make EFL/ESL students confident and effective in speaking and communication skills.

\section{The study has the following objectives:}

1. To find out the perceived psychological and linguistic obstacles and barriers that cause English communication apprehension and anxiety in Chinese EFL university learners.

2. To find out the perceived socio-cultural obstacles and barriers that induce communication apprehension and anxiety in Chinese EFL university learners.

\section{Literature Riview}

Apprehension have been perceived by many second language learners, as negatively impacting the cognitive process of language acquisition, and it holds the special place as being a highly examined variable in all of psychology (Horwitz, 1986). Psychologists make a distinction by dividing apprehension types in three categories: i.e., trait apprehension, state apprehension and situation specific apprehension (Spielberger (1983). 


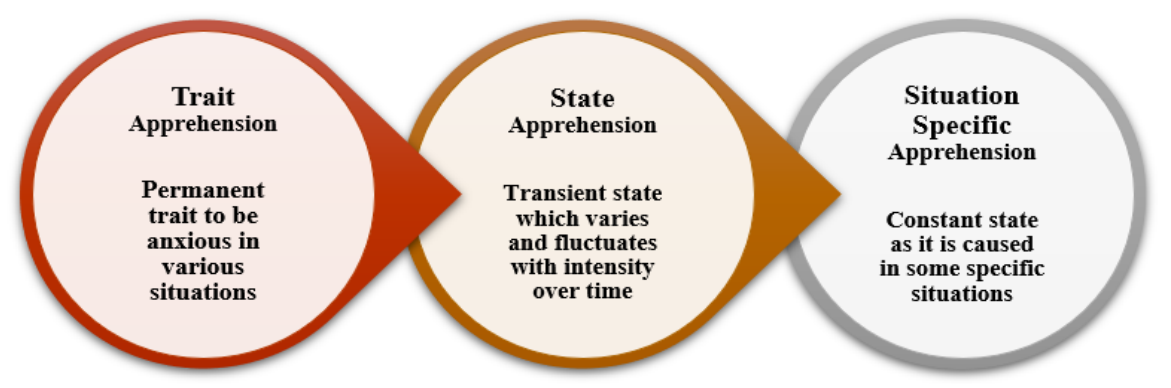

Figure 1

Types of communication apprehension

According to research, Confucian countries like Japan, Korea and China are more anxious in speaking FLS/SL (Woodrow, 2006).This apprehension affects their speaking and communication skills in terms of psychological, physiological, linguistics and many other socio-cultural aspects. It is the need of the hour that draconian measures should be taken to curb the debilitating effect of apprehension for effective communication skills in academia and professional field. Plethora of studies have studied and investigated the problem of $\mathrm{CA}$ and speaking anxiety and shed light on various reasons. These are student instructor related, personality factors like introvert or extrovert, shyness, lack of linguistics knowledge and socio-cultural like peers, parent influence or support, native speakers, etc (Asif et al. 2019; Irfan et al. 2020; Samad, Ali, \& Khan, 2021; Soomro et al. 2020). Besides some student related factors, many other environmental and external factors inducing CA , including lack of motivation and encouragement from instructors, and learners' indifferent personality and behaviour (Samad, 2014) Insufficient linguistic knowledge can cause speech and CA among EFL learners too (Asif et al. 2019). In their study, Kayaoğlu \& Sağlamel (2013) had an interview with 30 EFL Turkish participants and came to the conclusion that semantic, syntactic and phonetic problems were causes of communication anxiety and apprehension. Liu \& Jackson (2008) conducted a study among 547 Chinese EFL university students and deduced that pessimistic approach, fear of losing face and classroom ambiance were found as stress and apprehension inducers. Various studies have concluded that highly motivated and confident learners always perform better than those who are less confident and less motivated and have highlighted the importance of self-confidence and being motivated leads towards success (Asif et al. 2019; Noreen et al. 2019). Von Worde's (2003) study resulted in many factors as apprehension and anxiety causing among EFL learners. He adopted the qualitative approach and conducted an interview of 15 EFL university students and came to the conclusion that the fear of being negatively evaluated by others and peers, social anxiety, communication activities, inability to comprehend the second language lectures, classroom environment, and instructor's role were found to be as CA factors 


\section{The Pre-Frontal Cortex and Amygdala}

The two pivotal systems are responsible for generating and receiving language related apprehension, fear and anxiety i.e., pre-frontal cortex and amygdala.

\section{Prefrontal cortex}
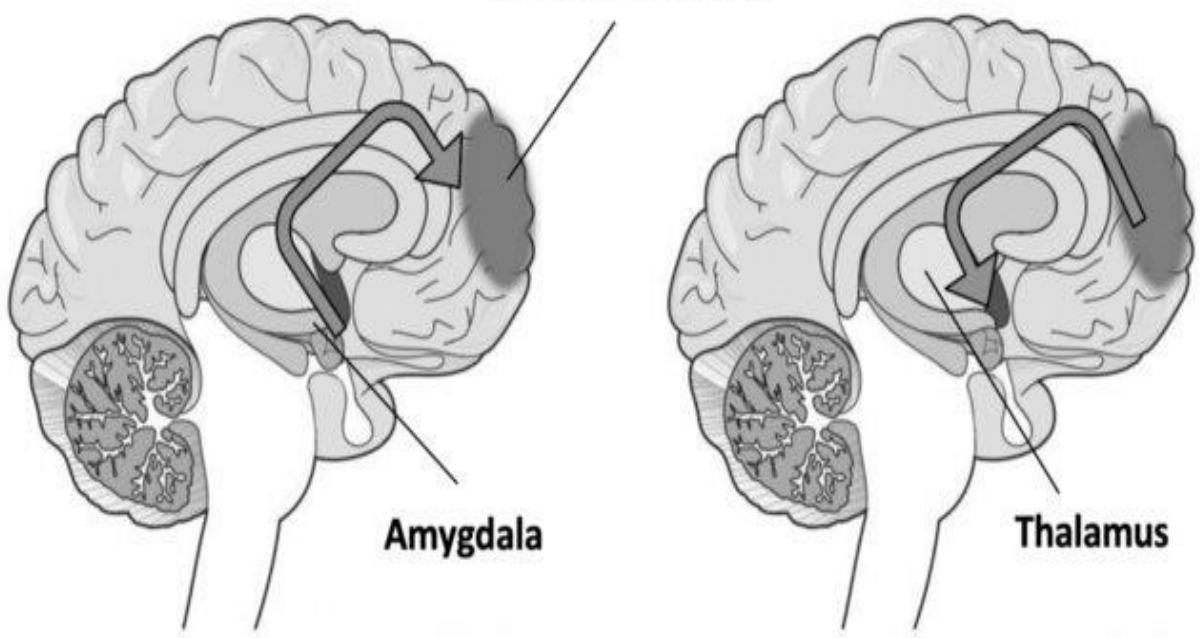

Figure 2

Sources of apprehension in the brain and their interdependence (Böttger \& Költzsch, 2020)

\begin{tabular}{|c|c|}
\hline Amygdala & Prefrontal Cortex (PFC) \\
\hline $\begin{array}{l}\text { responsible for emotions - } \\
\text { generates, receives, or changes anxiety } \\
\text { and anxious reactions, operates } \\
\text { unconsciously - } \\
\text { physical alarm system, perpetually scans } \\
\text { for incoming signals of danger - } \\
\text { affects the nervous system, hormones, } \\
\text { and the prefrontal cortex (PFC) - } \\
\text { generates anxiety without the influence of } \\
\text { the PFC and even overrules it - } \\
\text { anxieties are 'learned' and negatively } \\
\text { connoted }\end{array}$ & $\begin{array}{l}>\text { thinking brain - } \\
\text { responsible for cognition - } \\
\text { responsible for consciousness - } \\
\text { functions as executive (evaluation and } \\
\text { analysis) - } \\
>\text { promotes reasoning and logical thinking } \\
\text { - conscious memory (retrievable) - } \\
\text { contains detailed information - } \\
\text { capable of learning to control the } \\
\text { amygdala (aim of prevention and } \\
\text { therapy) - produces hypothetical bad } \\
\text { case scenarios }\end{array}$ \\
\hline
\end{tabular}

As CA and nervousness are a combined psychological phenomenon and construct, it widely originates from leaners' own self, perceptions, state of mind and as an intrinsic motivator; his perceptions and views about his fellows, friends, peers and instructors and his beliefs about speaking and communication situations in FL/SL (Scovel, 1994). CA could be a result of inadequate knowledge and command of second or foreign language and linguistic complexities (Samad, 2014; Samad et al. 2021). From the socio-cultural perspective, $\mathrm{CA}$ is experienced due to extrinsic motivators like different social and 
cultural environmental aspects, mother tongue and target language learning process Horwitz (1986). Since the FL/SL is an illustration of another culture, some people are bound to experience anxiety, apprehension and edginess as a result of their own reservations and concerns about foreign culture, ethnic issues and the like Horwitz (1986). Social status of the instructor, speaker and imbalance power relation between the both is also an important factor in inducing anxiety apprehension in speaking foreign language.

It is specifically so in China where a huge number of target language learners reside. Although in recent years, much significance has been given to the second or foreign language learning, writing and speaking in China, yet EFL Chinese learners have less contact with foreign, second or native speakers (Malik et al. 2020). There might be adequate literature related to anxiety factors. Still there is scarcity of many aspects based on foreign, second language CA and anxiety in Chinese context (Chen, 2019; Huang, Eslami, \& Hu, 2010; Shan, Hussain, \& Sargani, 2020; Wang \& Ding, 2001b; Yan, 2003). A thorough investigation of the factors could potentially contribute in existing literature and would assist language instructors in general and Chinese teachers in particular in mitigating CA and anxiety in academic settings, consequently to improve speaking and communication in TL. Horwitz (1986) states that some factors and practices are comfortable and convenient for one group of learners while to others may be a cause of stress, apprehension and anxiety. Taking some of the psychological, academic and socio-cultural discrepancies as a gap, the researchers decided to pursue the current investigation. This will contribute to the scarce literature that FL/SL has currently in Chinese context.

\section{Theoretical Framework of the Study}

In addressing the research questions related to apprehension and anxiety factors while communicating English as a second or foreign language, the researcher used the following theoretical frameworks.

The first framework is based on Horwitz's (1986) FLCAS deeming language apprehension and anxiety to performance and evaluation in a second, foreign language speaking and acquisition within social and academic context. The theory consists of three constructs i.e., CA, TA and FNE. The brief description of FLCAS will conceptualize the concept of communication apprehension. As the main purpose and focus of this study is on speech and communication anxiety and apprehension, so the first construct of Horwitz's theory will be discussed as compared to other two constructs. Horwitz, Horwitz and Cope (1986) state that CA may be confined to certain settings like stage fright, public speaking or in day-to-day conversation and communication or even a part of the general edginess or anxiety trait that manifests itself in many phases of a person's life.

In speaking or learning a second or foreign language, learners get nervous and experience anxiety in TL since they are not well familiar with it and their selfperceptions towards their peers, other people, friends and teachers results in apprehension. The second framework is related to Tanveer's (2007) factors that 
influence second language learning process. These three aspects are learners' selfperceptions, teacher's beliefs about academic environment, class management, classroom activities and methods. The first aspect of Tanveer's factors is about what perceptions of an EFL learner or an individual has about himself or herself. Apprehension begins when, how learners perceive and believe in themselves and how they want others to see them. It induces anxiety and apprehension when an EFL learner thinks that how people evaluate him when he or she communicates in second or foreign language. Tanveer (2007) asserts that second factor that instructor's perception and belief is also anxiety inducing when the teacher thinks that his role is solely to evaluate and pin point mistakes of students instead of facilitating them. The last factor is about classroom environment and procedure, various activities, speaking sessions and presentations in academic context often are anxiety inducing factors.

The third framework is related to Krashen's (1982) theory of second language acquisition. According to him, acquiring a language is not a conscious process rather a subconscious process, and it is the same subconscious process we all go through while acquiring our L1 or mother tongue. According to the literature, exposure to a language, without any doubt, is a vital ingredient in the learning of any language. Exposure to language in Krashen's theory is given the name of comprehensible input (S. Krashen, 1982). According to his comprehensible input hypothesis and low affective filter hypothesis; if there is a massive exposure to language and with low anxiety levels, positive attitude towards language acquisition, one can acquire SLA successfully.

Educational psychology has always been a difficult subject in the complicated nature of human psychology and human psyche. This complicated phenomenon maintains its significance in the language acquisition process as well. Language acquisition is not merely simple transmission of knowledge from encoder to decoders rather it is a complex process, which includes personal and social constructivism (Williams \& Burden, 1997). The fourth theoretical framework is related to social constructivism which sheds light on the acquisition of second language through environmental interaction than merely relying on the instructor and teaching methods in the classroom. Vygotsky and Feuerstein are two eminent figures in social constructivism. They claim that people do not learn language at their own, but they are born in the social world, and language acquisition is done through interaction with people (Presseisen \& Kozulin, 1992). Therefore, in this process, it could be said that teachers take the role of mediators in academics and act as mediators between a graduate or university study program, which could be considered as the social world learning from the social constructivist theory point of view. The word mediation has its roots in social interactionist approach to psychology (Fraser, 2006). In the language acquisition process teachers acts as mediators and according to Feuerstein and his mediation theory mediator plays a significant role in bridging the gap between the SL learners' acquisition inability and ability or what they feel they cannot do or they can do with little assistance (Grosser \& De Waal, 2008). Thus, significant people who are guiding from any perspective in learning are mediators and the experience shared by them is mediated learning experience (MLE). 


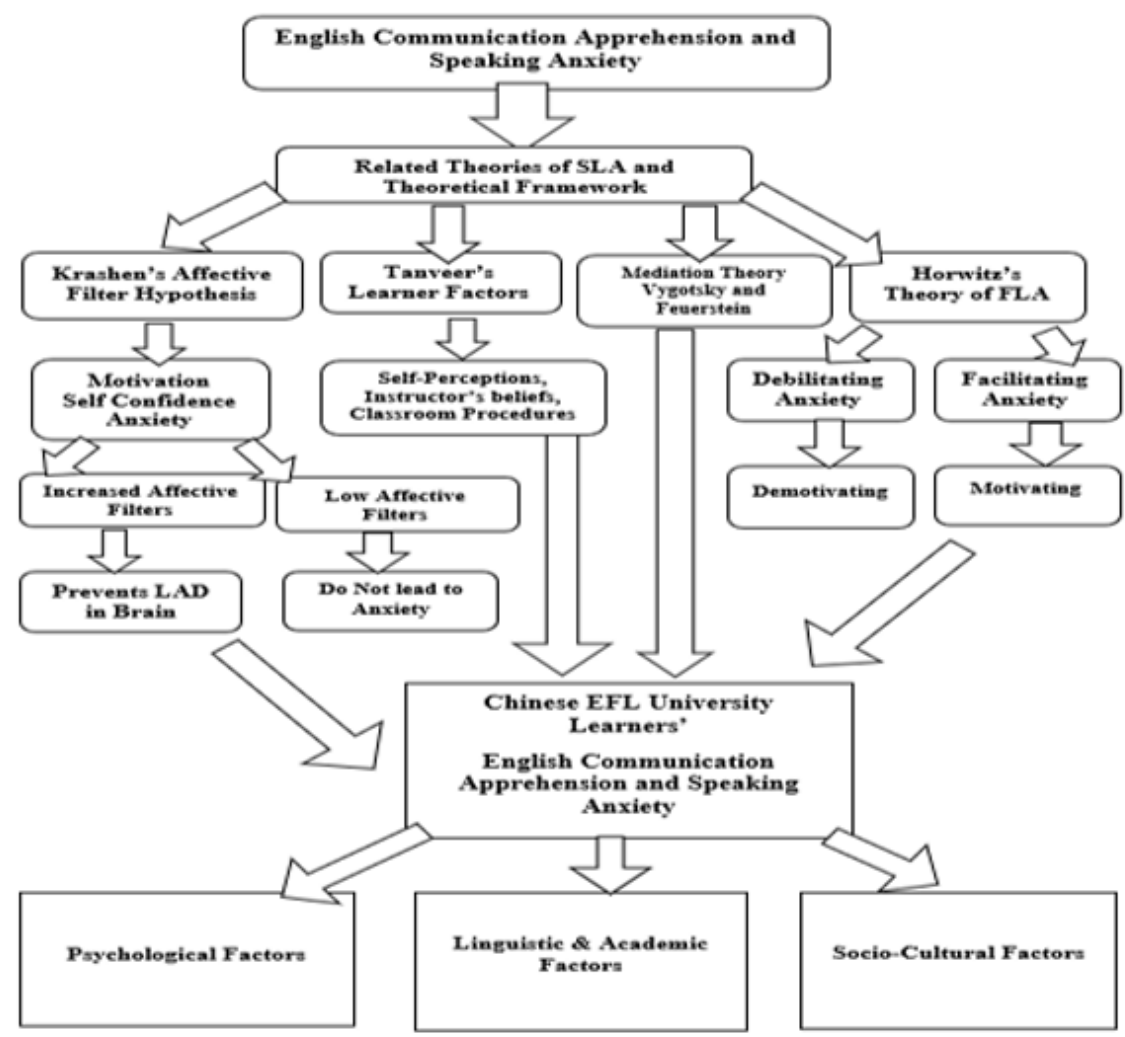

Figure 3

Theoretical framework and priori themes in Chinese EFL learners's CA

Based on the theoretical framework and existing literature, the present study sets out to answer the following questions:

\section{Research Questions}

1. What are the perceived psychological and academic obstacles or barriers that induces English communication apprehension in Chinese EFL university learners?

2. What are the perceived socio-cultural barriers that cause English communicationapprehension in Chinese EFL university learners?

\section{METHOD}

The current research is based on empirical-theoretical framework, thus exploratory in nature, and has adopted epistemological approach as a qualitative method for data analysis. In this study, semi-structured interviews and focus group discussion were conducted for qualitative data collection to get the better understanding of the speaking 
and apprehension anxiety factors. Consequently, the utilization of interviews was in accordance and in line with the assumptions related to epistemological and ontological perspective that knowledge is gained mutually through interaction between the interviewer and interviewee or the researcher and the respondent. A Focus group discussion and semi-structured interviews were conducted with eight, Chinese EFL university learners aged between (20-25), a sample representing the ideal model suggested in the existing literature for group size (Adams \& Cox, 2008). These EFL Chinese university students were indigenous of Hubei province, belonging to different cities but enrolled in the same public university in Wuhan city, which is considered metropolitan and educational hub of Central China where students usually enjoy a better foreign language acquisition environment and have a possibility to access native and non-native English speakers as compared to other cities. The EFL respondents were attending oral communication skills course in the department of foreign languages for one semester. According to Gubrium \& Holstein (2001) focus group discussion and interview is the best technique to get an insight of the many complex underlying themes. Before starting the final interviews, a pilot or trail run was performed with EFL university students as suggested by Dörnyei, (2014). After finalizing the questions for final interview, the researchers conducted the final interviews. The interviews were recorded and transcribed. For each participant 40 to 45 minutes were allocated for an interview.

\section{Data Analysis}

This study adopted directed content analysis in which theories and existing literature studies are employed to inform the codes and themes initially utilized in analysis (Elo \& Kyngäs, 2008). The findings from the directed content analysis are expected to build on the relevant existing knowledge base. This approach is highly feasible for the current study due to the deductive approach and the unit of analysis in this study were themes (the basic unit of the text that will be classified) themes can be expressed in various physical linguistic units, whether it is a single word, phrase, sentence or a paragraph, thus code was assigned to any part of the text that gave an idea expressed in a theme related to the study. These themes were developed on the basis of inducting coding along with deductive coding. The researcher used both deductive and inductive approaches. Inductive reasoning employs the data to generate ideas or hypothesis development whereas, deductive approach starts with the idea and utilizes the data to confirm, support or negate the idea/hypothesis testing (De Vaus, 2008). The researcher employed (deductive technique) mainly because it was part of the directed content analysis (exploring how various ideas in existing literature were observed in the qualitative data collected) while, analysing the data to dig out recurring themes that were independent of pre-existing body of theoretical concepts (inductive technique). As this study used directed content analysis and thus demand early direction, a priori themes were developed in this study besides initial codes by the researcher. According to Talmy \& Richards (2011) qualitative data analysis is a systematic procedure of separating research data into different parts or units. The researcher examines the various parts and then assemble the data in a meaningful way. MS word document was also used for all transcribed data and researchers got printed form for coding and 
making list of major themes. the transcripts were read from beginning to the end minutely to gain a sense of the interview as a whole (Alshenqeeti, 2014). The research questions were utilized as guideline on what to categorize and what to code. In content analysis, codes (labels) are assigned to the parts of the texts to help list the key concepts while maintaining the context of the concepts. The researchers developed the coding scheme (coding manual/codebook), listing categories/codes and their relevant definition and tried to maintain consistency in coding according to the existing literature (Hsieh \& Shannon, 2005). The process of coding was guided by various studies (Armat et al. 2018; Samad, 2014). Data reduction consists of precising the data by reading many times and making list of codes. By utilizing these codes and priori themes the researcher with the assistance of another researcher identified, and prepared an initial codebook and coding scheme as an initial guidebook to be used in coding process. It was based on several meta codes and sub codes representing general theme. By employing inductive technique along with deductive the researchers arranged certain code hierarchically to develop the relation between several codes. There are three types of reliability 1) stability which represents if the coder's use of categories or codes changes with the passage of time 2) accuracy where a gold standard coding scheme is already developed with maximum reliability and rest of coding schemes are developed for comparison with it 3) The last is reproducibility across coders, sometimes called intercoder reliability, its main concern is whether the various coders would code the almost same data throughout the process (Krippendorff, 2004). This study was concerned with third type and establishing coding scheme that are reproducible for semi-structured interviews of the focus groups. The coding consists of particular words, or phrase, so that they could represent a specific construct, moreover, the related statement should go under the relevant code category (Newcomer, Hatry, \& Wholey, 2015). The first researcher discussed the coding scheme with the second researcher (helper) to compare the coding scheme. There were some discrepancies, ambiguities and intercoder reliability was low therefore, based on discussion the coding scheme was refined revised, modified codes/categories until the acceptable level of reliability was obtained (Krippendorff, 2004). The last phase or conclusion means to deduce results and answer the research questions on the basis of several categories or sub-categories.

\section{FINDINGS}

Findings indicated that perceived hindrances affecting EFL Chinese university learners can be described into three significant categories based on the priori themes and frequency of the responses: perceived psychological, perceived linguistic or academic and perceived socio-cultural hindrances that cause CA and anxiety among EFL Chinese university learners.

\section{RQ1. Perceived Psychological Obstacles}

\section{Shyness and Introversion}

The study has identified various themes triggering FL or EL communication apprehension and anxiety in EFL Chinese university learners. One of these is shyness 
and an introvert personality. According to interviewees they often want to remain unnoticed and unobserved due to their shy and introvert nature.

“...I always feel shy and being bashful I hesitate to talk in English because I know I cannot speak fluently..." (7/8).

This is in line with the seminal work of Liu (2008), who identifies personality traits as one of the most pivotal factor in triggering reticence in foreign language

\section{Lack of Self-Confidence}

Chinese participants said that they often feel that their confidence is shaking and they are unable to convey their message and communicate when self-confidence is low. According to the participants:

"When I cannot pronounce words in English properly, I lose confidence and feel highly nervous due to mispronunciation and wrong usage of grammar...” (6/8).

They agreed upon the fact that self-confidence is the key to speaking and communicating effectively. This finding is in line with recent study of Wu's, (2019b) in which he found Chinese university learners as reticent to speak in FL effectively as being unconfident.

\section{Inferiority Complex}

According to Chinese EFL respondents, some students are quick learners and gifted with sharp memory and they can get the desired results with less efforts. Some students are slow learners and they need to put more efforts for language acquisition. The majority felt inferiority complex because they thought their peer group fellows were more intelligent, fluent and talented in these aspects of English. Participants also reported that they desperately lacked in effective speaking skills and English communication in front of those who were highly proficient users.

"I feel quick brain response is very important, sometimes my brain gets stuck in thinking...unlike my other classmates... who are quicker in answering questions in English class...they are fluent in English and talented... when I answer one sentence in English...it takes time to answer second time in English...I think a lot, think in Chinese and then... try to translate in English .... I am not like my other classmates..." (7/8).

The above mentioned statements mirrored the conclusions drawn by researchers in few studies (Yan \& Horwitz, 2008b).

\section{Apprehension and Anxiety}

Students also regarded CA as one of the perceived psychological barriers and they said they feel more anxiety in listening and speaking English as compared to writing and reading.

"When teacher asks me to speak...I feel afraid of speaking and suddenly feeling of anxiety overcomes me, my mouth gets dry... and I look here and there ... who is 
listening and looking towards me...I get nervous and my heart throbs because... I feel others will laugh on me...this is very strange feeling... difficult to overcome in English lecture.... I cannot get success and competence in English speaking." (6/8).

This finding is in line with the seminal work of Wu (2019a).

\section{Comparison with other Fellows and Peers}

Some Chinese students perceived and strongly believed that their contemporary fellows and peers had strong grip on English speaking skills and vocabulary and this difference was a great source of anxiety for them. Chinese respondents stated:

"When an English instructor asks something...other peers are more confident and willing to answer...and they speak fluently...I am often stuttering and unwilling to participate...there is an evident difference... group discussion and presentation I try to avoid...my friends and peers are good at speaking...I am afraid that others will laugh on me and think my English is too poor..." (7/8).

The majority of the students agreed upon the fact that they get nervous when they are being evaluated by their class fellows, friends and peers inside and outside class due to insufficient English language skills in speaking. These finding are in line with previous studies conducted in Chinese context (Yan \& Horwitz, 2008b).

\section{Perceived Linguistic and Academic Obstacles}

Besides being negatively evaluated by peers, fellows and fear of committing mistakes while speaking and communicating in English language, the Chinese students reiterated some linguistic and academic difficulties, which cause anxiety and apprehension too. The psycholinguists and researchers have frequently stated that English as a second language has difficult, complex system of pronunciation and it's difficult to master like a native speaker.

\section{Lack of SL Vocabulary}

The participants' responses with regards to vocabulary, difficulty in revising, remembering and retrieving it is also in line with past studies (Yan \& Horwitz, 2008; Tanveer, 2007). One participant reported:

"I always feel edginess and hesitation in speaking English because I think...I always forget words in English... I don't find enough words to express my ideas and cannot convey my message due to lack of vocabulary in English language... it's hard for me." (7/8)

They stated that sometime is hurry, we forget even simplest words and feel anxiety upon that situation. This is in line with previous studies that there exists a significant correlation between second language vocabulary and language anxiety (Asif et al. 2019). 


\section{Lack of SL Lexical and Grammar Knowledge}

Based on the results of this research, lexical and grammar knowledge of second language has also been appeared as a main source of communication or speaking anxiety and apprehension. Past studies also regarded grammar knowledge of SL as anxiety inducing factor $(\mathrm{Wu}, 2019$; Tanveer, 2007). If the second language learners are over anxious about grammar rules they often fail to communicate effectively. The majority of the participants were of the view:

"Whenever I want to communicate with my friends and in second language, I always feel in advance that my grammatical knowledge is incorrect, wrong use of tenses, passive voice...It just makes me feel so unconfident and confused... I have little knowledge about parts of speech and other features of grammar... I need a lot of practice...It causes tension and nervousness to me..." (7/8).

This finding is reaffirmed in the studies by Wu (2019b) Asif et al. (2020) and Malik et al. (2021) that the students feel anxious about lexical and grammar rules.

\section{Pronunciation}

Pronunciation is an essential and significant factor across different language learners and groups because it casts direct and immediate effect on others when they interact a person. Sometimes when one individual cannot understand another, he or she needs to immediately correct his or her pronunciation which is often a very difficult. All the participants agreed upon the fact that poor pronunciation causes anxiety and fear of being misunderstood.

"I am afraid to talk with others especially if he or she has a native like accent, or with natives. I am confused and feel hesitation and fear in talking... I am sure, they cannot understand my pronunciation which is so poor... It takes time to speak if I speak with natives and others in English." (8/8)

This finding is in line with seminal work of Y. Chen's (2005) findings which confirms the above finding that lack of lexical knowledge and poor pronunciation is fear and anxiety inducing factor in speaking English in Chinese EFL university learners.

\section{English Language Classroom and Instructor}

The formal and strict classroom environment can be a source of debilitative anxiety in speaking. In this study Chinese university EFL learners confirmed that formal and judgement classroom induces considerable apprehension for them. The students may get emotionally disturbed. They also added that an authoritative instructor can be anxiety provoking factor. According to them:

“We don't feel comfortable if English classroom environment is strict and formal and instructor does not motivate students... sometimes we are just passive listeners and speak nothing in English language lecture..." (6/8). 
This finding is paralleled in a number of other research findings related to the crucial role of language educators and English instructors as their motivation, encouragement and positive attitude can play a significant role in developing effective communication skills (Tanveer, 2007; Wu2019a ).

\section{RQ2-Socio-Cultural Perceived Obstacles}

\section{Lack of Comprehensible Input}

The role of SL exposure has been emphasized under the name of Stephen Krashen's (1986) famous SLA theory and its hypothesis of comprehensible input. Other than classroom teaching there could be other tools for comprehensible input and exposure to TL which can give maximum output and viable outcomes. However, Chinese learners reported that due to less interaction with foreigners, insufficient use of social media in English language, reading books and watching movies and television in their Chinese language, they feel communication anxiety and apprehension.

"Out of the class... I do not interact with foreigners due to my poor English language and other modes of communication are also not in English. on WeChat I use Chinese, I listen news and talks in Chinese. Out of the class my class fellows and friends do not speak English..." (7/8)

The above findings suggest that limited exposure to english in class and out of class and lack of comprehensible input is a serious obstacle in developing effective communication skills. It suggests more exposure to TL is essential for effective English communication. This finding supports the previous studies with regards to the significant role of exposure to English (Tanveer, 2007b).

\section{Role of Parents}

In the current study the role of parents and their influence has been found to be another important factor that could play a significant role in either aggravating students' language anxiety or reducing communication apprehension. According to Chinese respondents:

"My parents were not aware of the growing need of English language...they never sent me to English speaking school in childhood. they didn't motivate much to learn and speak English ...therefore... I am not confident; I feel anxiety in English communication..." (7/8).

The findings indicated Chinese EFL university learners' parents can also affect their foreign or second language acquisition process. This finding is in line with previous studies (Samad, 2014).

some students also reported:

"This is very important for you to learn English and speak ... if you want to be successful in future and travel abroad. you must learn...they always motivated, encouraged me to speak and communicate in English... I can speak well now..." $(6 / 8)$. 


\section{Geographic Background and Place of Origin}

Students' geographical background and place of origin has also been associated with their communication and speaking ability and may influence in a number of ways. This is in line with (Samad, 2014). The participants stated:

"He gets upset, when he comes to know that... his any urban classmates or friends had learnt English from some good institutes, or in a metropolitan city... he feels that they are better in communication and English speaking than he is and he belongs to rural area." (5/8).

\section{Cultural Alienation}

Along with other factors as source of CA and anxiety, this study also found out that some Chinese students think that if they learn or speak English language, they will lose their cultural values. Some of the respondents expressed negative perceptions for SL learning and speaking. According to Chinese respondents:

"Sometimes they feel more inclined towards Western culture and English language and it seems as If they will lose their cultural identity..." (3/8).

However, the majority of the Chinese participants expressed positive attitude in speaking and learning English as need of the hour.

"As a lingua franca... I think English should be learnt without any apprehensive views to compete with rest of the world..." (7/8).

This finding is paralleled with the study of Yan \& Horwitz's, (2008b).

\section{DISCUSSION}

The position of CA and anxiety in the current model suggests that Chinese EFL university learners perceived SA as a consequence of psychological, linguistic and socio-cultural barriers. These factors are highly associated with Chinese EFL learners' self-perceptions and beliefs, about classroom environment and instructor's beliefs, hence the results support the theoretical model of Tanveer's (2007b). According to which CA begins how these EFL students feel about themselves and how they want others to think about them when they use FL/SL. In the current study Chinese EFL learners felt reticence in class while talking in front of other class mates, language instructors and they had fear of being negatively evaluated by others due to lack of selfefficacy, low esteem and confidence. This finding supports the theory of E. K. Horwitz's (1986) that FLA is unique and SPA. These findings also support the other empirical studies in existing literature (Naudhani, Wu, \& Naudhani, 2018; Wu, 2019). The findings of the current study also confirmed the SLA theory of S. Krashen's (1982) if there is a lack of comprehensible input and affective filters are high then learners' acquisition process is hindered by anxiety, low self-confidence and lack of motivation. The results of DCA showed that majority of respondents agreed that they experienced low self-confidence and lack of motivation due to insufficient comprehensible input and exposure to English. In addition to it, the results of this study also indicated that shy 
personality, introvert nature and other personality traits caused psychological barriers and anxiety in Chinese EFL university learners which are in line with the study of Liu (2008) who identified self-perceptions and personality traits an important factors in provoking reticence in EFL learners. Furthermore, the findings of this study have also shed light on linguistic factors like poor grammatical and lexical knowledge also induced CA and these findings are in consistent with Wu's (2019a) study. Lastly, the findings also indicated that some socio-cultural factors like lack of exposure to English, parental educational status, geographical background and cultural alienation caused apprehension and these findings are in line with previous studies (Tanveer, 2007b). The findings of this study also supports the mediation concept in social constructivism given by Vygotsky's (1980) and Feuersvin's (1990) according to which people do not learn language at their own, but they are born in the social world, and language acquisition is done through interaction with people and the parents or teachers act as mediators (Fraser, 2006). According to Feuerstein and his mediation theory mediator plays a significant role in bridging the gap between the SL learners' acquisition inability and ability or what they feel they cannot do or they can do with little assistance (Grosser \& De Waal, 2008). More comrehensible input and exposure are needed in and out of class to address CA.

\section{CONCLUSION AND RECOMMENDATIONS}

The different themes generated from Chinese participants interview can be a frame work for future research. The directed content analysis shows that if at one hand Chinese learners are nervous and feel CA in SL, but on the other hand, they have passion, enthusiasm and positive attitude too to learn and speak EL effectively. They believe that parents' educational status, maximum exposure to EL in and out of class, teachers' motivation and encouragement can be very helpful in overcoming psychological, linguistics and socio-cultural obstacles in CA. They feel lack of confidence because of their poor lexical and linguistic knowledge in FL. This lack of confidence is a serious threat to university learners' speaking skills and communicative behaviour in SL speaking class. Language educators should prepare them to acknowledge the fact that speaking process is not possible without errors, mistakes and therefore, they can overcome these pitfalls and mistakes by doing maximum practice of oral communication skills in and out of class. With low affective filters, more comprehensible input and social interaction students can improve their communication skills in EL. Lastly, the instructors should be well acquainted with the geographical differences of EFL learners so that the communicative behaviours related to CA can be tackled and identified easily. In SL/FL, speaking and listening are two essential skills while the language instructors pay more attention to reading and writing skills, it is suggested that language educators should plan their lessons and language lectures keeping the anxiety issues and affective variables into consideration and that can motivate students to speak maximum and confidently without fear of being negatively evaluated.

\section{LIMITATIONS}

The current study is limited in sample, a focus group discussion and semi-structured interviews $(\mathrm{N}=8)$ due to time constraints taken from one of the public universities in 
Wuhan. The findings of this research however, cannot be generalized to all population of EFL university learners. Moreover, the study is qualitative in nature. It would have been better if the quantitative approach had been included, which could not be a part of this study due to time constraints.

\section{REFERENCES}

Alshenqeeti, H. (2014). Interviewing as a data collection method: A critical review. English Linguistics Research, 3(1), 39-45.

Asif, M., Zhiyong, D., Azhar, A., \& Malik, S. (2019). Spelling Errors among Online Learners in the Moderated Discussion Board: A Case Study of Virtual University of Pakistan. European Online Journal of Natural and Social Sciences, 8(2), pp-212.

Asif, M., Zhiyong, D., Malik, S., \& Zaman, B. (2019). THE STUDY OF ERROR ANALYSIS OF PAKISTANI L2 LEARNERS IN ENGLISH COMPOSITIONS.

Böttger, H., \& Költzsch, D. (2020). The fear factor: Xenoglossophobia or how to overcome the anxiety of speaking foreign languages. Training, Language and Culture, 4(2).

Chen, C. (2019). A Comparative Study of Online Teacher-Involved and Peer Interactive Learning: Chinese EFL Students' Perceptions and Practices. Journal of Educational Technology and Online Learning, 2(1), 56.

Chen, Y. (2005). Barriers to Acquiring Listening Strategies for EFL Learners and Their Pedagogical Implications. Tesl-Ej, 8(4), n4.

De Vaus, D. (2008). Comparative and cross-national designs. The SAGE Handbook of Social Research Methods, 249-264.

Dörnyei, Z. (2014). Researching complex dynamic systems:'Retrodictive qualitative modelling'in the language classroom. Language Teaching, 47(1), 80.

Elo, S., \& Kyngäs, H. (2008). The qualitative content analysis process. Journal of Advanced Nursing, 62(1), 107-115.

Feuersvin, T. (1990). The theory of structural cognitive modifiability. REPORT NO PUB DATE NOTE AVAILABLE FROM, 68.

Fraser, H. (2006). Helping teachers help students with pronunciation: A cognitive approach.

Gökcan, M., \& Aktan, D. Ç. (2019). Development of Exposure to English Scale and Investigation of Exposure Effect to Achievement. International Journal of Assessment Tools in Education, 6(1), 109-124.

Grosser, M., \& De Waal, E. (2008). Recentering the teacher: From transmitter of knowledge to mediator of learning. Education as Change, 12(2), 41-57.

Gubrium, J. F., \& Holstein, J. A. (2001). Handbook of interview research: Context and method. Sage Publications. 
Horwitz, E. K. (1986). Preliminary evidence for the reliability and validity of a foreign language anxiety scale. Tesol Quarterly, 20(3), 559-562.

Hsieh, H.-F., \& Shannon, S. E. (2005). Three approaches to qualitative content analysis. Qualitative Health Research, 15(9), 1277-1288.

Irfan, F., Abbas, F., Talib, N., \& Hussain, T. (2020). ANALYSINGENGLISH LANGUAGE TEACHING LEARNING PROCESS IN PUBLIC SECTOR SCHOOLS IN PAKISTAN. Psychology and Education Journal, 57(9), 5328-5344.

Jie, L., \& Xiaoqing, Q. (2006). Language learning styles and learning strategies of tertiary-level English learners in China. RELC Journal, 37(1), 67-90.

Jing, H., \& Junying, Z. (2016). A Study on Anxiety in Chinese EFL University Students. 9(9), 179-184. https://doi.org/10.5539/elt.v9n9p179

Kayaoğlu, M. N., \& Sağlamel, H. (2013). Students' perceptions of language anxiety in speaking classes. Journal of History Culture and Art Research, 2(2), 142-160.

Krashen, S. D. (1982). Acquiring a second language. World Englishes, 1(3), 97-101.

Krippendorff, K. (2004a). Measuring the reliability of qualitative text analysis data. Quality and Quantity, 38, 787-800.

Liu, M., \& Jackson, J. (2008). An exploration of Chinese EFL learners' unwillingness to communicate and foreign language anxiety. The Modern Language Journal, 92(1), 7186.

Malik, S., Qin, H., Asif, M., \& Khan, S. M. (2020). An Investigation of Xenoglossophobia among Chinese Postgraduates. European Online Journal of Natural and Social Sciences, 9(1), pp-104.

Malik, S., Qin, H., Muhammad khan, S., \& Ahmed, K. (2020). Quantitative Analysis of the Foreign Language Anxiety: Chinese and Pakistani Postgraduates in Focus. Arab World English Journal. https://doi.org/10.24093/awej/vol11no1.23

Malik, S., Qin, H., Oteir, I., \& Soomro, M. A. (2021). Detecting Perceived Barriers in FLSA: The Socio-Psycholinguistic Study of EFL University Learners. Advances in Language and Literary Studies, 12(1), 34-45.

McCROSKEY, J. C. (1977). ORAL COMMUNICATION APPREHENSION: A SUMMARY OF RECENT THEORY AND RESEARCH. Human Communication Research. https://doi.org/10.1111/j.1468-2958.1977.tb00599.x

Naudhani, M., Wu, Z., \& Naudhani, S. (2018). Exploring the Factors of Foreign Language Anxiety Among Chinese Undergraduate English Majors and Non-English Majors. 8(5), 142-150. https://doi.org/10.5539/ijel.v8n5p142

Newcomer, K. E., Hatry, H. P., \& Wholey, J. S. (2015). Conducting semi-structured interviews. Handbook of Practical Program Evaluation, 492.

Noreen, S., Wei, F. W., Zareen, M., \& Malik, S. (2019). The Intercultural Adjustment 
of Pakistani Students at Chinese Universities. INTERNATIONAL JOURNAL OF ACADEMIC RESEARCH IN BUSINESS AND SOCIAL SCIENCES, 9(3).

Presseisen, B. Z., \& Kozulin, A. (1992). Mediated Learning--The Contributions of Vygotsky and Feuerstein in Theory and Practice.

Samad, A. (2014). An exploratory investigation of foreign language classroom speaking anxiety amongst Pakistani EFL university students.

Samad, A., Ali, M., \& Khan, A. K. (2021). An Exploration of Classroom-related Sources of Foreign Language Speaking Anxiety of Pakistani University Students. Sjesr, $4(1), 211-221$.

Scovel, T. (1994). The role of culture in second language pedagogy. System, 22(2), 205-219.

Shan, C., Hussain, M., \& Sargani, G. R. (2020). A mix-method investigation on acculturative stress among Pakistani students in China. PloS One, 15(10), e0240103.

Soomro, M. A., Ahmed, A., Siming, I. A., \& Ali, M. (2020). Towards Investigation of Instructional "Hiccups" of ELT Fraternity in EFL classroom. Journal of Language and Cultural Education, 8(3).

Talmy, S., \& Richards, K. (2011). Qualitative interviews in applied linguistics: Discursive perspectives. Applied Linguistics, 32(1).

Tanveer, M. (2007b). Investigation of the factors that cause language anxiety for ESL / EFL learners in learning speaking skills and the influence it casts on communication in the target language . By. (June), 1-92. https://doi.org/10.13140/RG.2.1.1995.1129

Tian, Z., Wei, Y., \& Li, F. (2019). Who are better teachers? The effects of tenure-track and part-time faculty on student achievement. China Economic Review, 53, 140-151.

Von Worde, R. (2003). Students' Perspectives on Foreign Language Anxiety. Inquiry, $8(1), \mathrm{n} 1$.

Vygotsky, L. S. (1980). Mind in society: The development of higher psychological processes. Harvard university press.

Wan, H., Yan, L., \& Gong, Y. (2020). Two Major Factors that Lead to English Speaking Anxiety. 2020 3rd International Conference on Humanities Education and Social Sciences (ICHESS 2020), 661-665. Atlantis Press.

Wang, Q., \& Ding, X. (2001). Language anxiety among rural middle school students in west China. Journal of Northwest Normal University, 38(5), 68-73.

Williams, M., \& Burden, R. L. (1997). Psycology for language teachers. Ernst Klett Sprachen.

Woodrow, L. (2006). Anxiety and speaking English as a second language. RELC Journal, 37(3), 308-328. https://doi.org/10.1177/0033688206071315 
Wu, H. (2019a). Reticence in the EFL Classroom: Voices from Students in a Chinese University. International Journal of Applied Linguistics and English Literature, 8(6), $114-125$

Yan, J. X., \& Horwitz, E. K. (2008a). Learners' perceptions of how anxiety interacts with personal and instructional factors to influence their achievement in English: A qualitative analysis of EFL learners in China. Language Learning, 58(1), 151183. https://doi.org/10.1111/j.1467-9922.2007.00437.x 